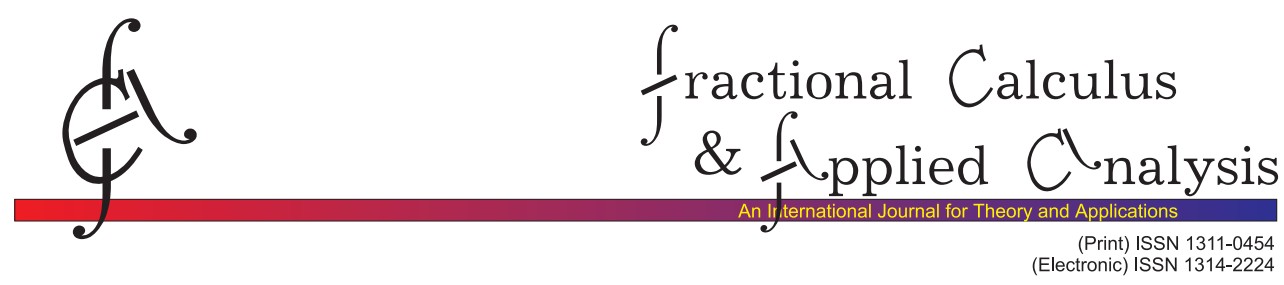

CONTENTS - FCAA, Vol. 20, No 4 (2017)

Editorial: FCAA RELATED NEWS, EVENTS AND BOOKS

(FCAA-Volume 20-4-2017)

825

L. D'Onofrio, A. Fiscella, G. Molica Bisci PERTURBATION METHODS FOR NONLOCAL KIRCHHOFF-TYPE PROBLEMS

\title{
A. Giusti
}

ON INFINITE ORDER DIFFERENTIAL OPERATORS IN

FRACTIONAL VISCOELASTICITY

M. Ferreira, M.M. Rodrigues, N. Vieira

FUNDAMENTAL SOLUTION OF THE

MULTI-DIMENSIONAL TIME FRACTIONAL

TELEGRAPH EQUATION

J.A. Gallegos, M.A. Duarte-Mermoud ROBUSTNESS AND CONVERGENCE OF FRACTIONAL SYSTEMS AND THEIR APPLICATIONS TO ADAPTIVE SCHEMES 895

D. Boyadzhiev, H. Kiskinov, M. Veselinova, A. Zahariev STABILITY ANALYSIS OF LINEAR DISTRIBUTED ORDER FRACTIONAL SYSTEMS WITH DISTRIBUTED DELAYS

M. Bergounioux, A. Leaci, G. Nardi, F. Tomarelli FRACTIONAL SOBOLEV SPACES AND FUNCTIONS OF BOUNDED VARIATION OF ONE VARIABLE

Y.-K. Chang, A. Pereira, R. Ponce APPROXIMATE CONTROLLABILITY FOR FRACTIONAL DIFFERENTIAL EQUATIONS OF SOBOLEV TYPE VIA PROPERTIES ON RESOLVENT OPERATORS 963

(Continued on back cover page) 
CONTENTS, continued:

Yu. Kolomoitsev

ON MODULI OF SMOOTHNESS AND

AVERAGED DIFFERENCES OF FRACTIONAL ORDER ...... 988

C. Gong, W. Bao, J. Liu

A PIECEWISE MEMORY PRINCIPLE FOR

FRACTIONAL DERIVATIVES

B.P. Moghaddam, J.A.T. Machado A COMPUTATIONAL APPROACH FOR THE SOLUTION OF A CLASS OF VARIABLE-ORDER FRACTIONAL INTEGRO-DIFFERENTIAL EQUATIONS WITH WEAKLY SINGULAR KERNELS 1023

\section{Bota, B. Căruntu}

ANALYTIC APPROXIMATE SOLUTIONS FOR

A CLASS OF VARIABLE ORDER FRACTIONAL DIFFERENTIAL EQUATIONS USING

THE POLYNOMIAL LEAST SQUARES METHOD ........... 1043

Y. Jiao, D. Zhou, F. Weisz, Z. Hao CORRIGENDUM: FRACTIONAL INTEGRAL ON

MARTINGALE HARDY SPACES WITH

VARIABLE EXPONENTS 


\section{ABOUT "FCAA" JOURNAL}

The "FCAA" journal, abbreviated as "Fract. Calc. Appl. Anal.", Print ISSN 1311-0454, Electronic ISSN 1314-2224, is a specialized international journal for theory and applications of an important branch of Mathematical Analysis (Calculus), where the differentiations and integrations can be of arbitrary non-integer order. A peer-reviewed journal with high standards guaranteed by the Editorial Board's list and carefully selected external referees and proven by the recently achieved high values of: Thomson Reuters Impact Factor (JIF) = 2.974 (2013), 2.245 (2014), 2.246 (2015); Scopus Impact Rang (SJR) = 2.106 (2013), 1.433 (2014), 1.602 (2015), launching "FCAA" to top 10 places in the ranking lists for Maths and Appls.

Abstracted / Indexed in:

ISI Science Citation Index Expanded and Journal Citation Reports/Science Edition (Thomson Reuters); Scopus (Elsevier); SCImago (SJR); WorldCat (OCLC); Mathematical Reviews (MathSciNet); Zentralblatt Math.; Summon (Serials Solutions / ProQuest); Primo Central (ExLibris); Celdes; JournalTOCs; Google Scholar; etc.

Established in 1998, Founding Publisher: (Vol. 1-Vol. 13, till 2010) Institute of Mathematics and Informatics - Bulgarian Academy of Sciences. Contents and abstracts of all volumes, back volumes 2005-2010, and journal's details are available at Editor's websites:

http://www.math.bas.bg/ fcaa, http://www.diogenes.bg/fcaa.

Co-published in the period 2011-2014, Vol. 14-Vol. 17, by: Versita $=$ De Gruyter Open, Warsaw and Springer-Verlag, Wien, Website (former): http://http://degruyteropen.com/serial/fcaa/ and Online Electronic version then was at SpringerLink.

Current Publisher - since 2015, Vol. 18:

Walter de Gruyter GmbH, Berlin / Boston,

Publisher's website: http://www.degruyter.com/view/j/fca

$$
=\text { http://www.degruyter.com/fcaa }
$$

with all journal's details and online electronic version (Vols. 14-17, free).

Published with the kind assistance and cooperation of: Institute of Mathematics and Informatics - Bulgarian Academy of Sciences.

To Order: Contact Kathrin Müllenbach, LL. M., De Gruyter, Genthiner Strasse 13, 10785 Berlin, Germany; Tel.: +49 (0) 30260 05-350, Fax: +49 (0) 30260 05-264, E-mail: kathrin.muellenbach@degruyter.com

To Submit: Electronically to Editor-in-Chief, virginia@diogenes . bg (Virginia Kiryakova). Follow Instructions to Authors, use Authors' Kit.

Publisher and Distributor, since 2015:

Walter de Gruyter GmbH, Berlin / Boston 


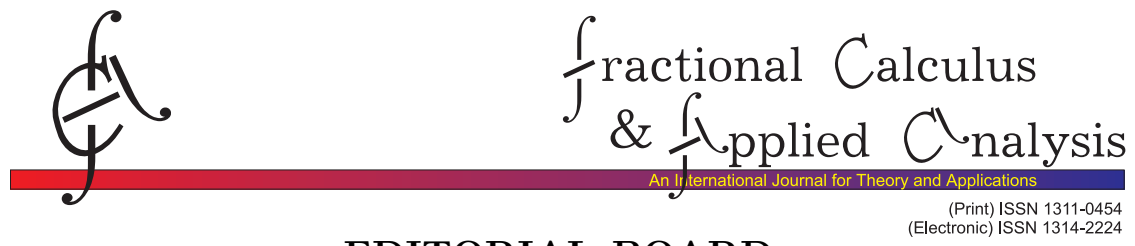

EDITORIAL BOARD

\section{Editor-in-Chief: Virginia Kiryakova}

Editorial Office:

Institute of Mathematics and Informatics - Bulgarian Academy of Sciences

"Acad. Georgi Bontchev" Str., Block 8, Sofia - 1113, Bulgaria

E-mail: virginia@diogenes.bg, fcaa@math.bas.bg ; Fax: +359-2-9478608

Honorary Founding Editors $\ddagger$ were:

Anatoly A. Kilbas ${ }^{\ddagger}$ (Belarus), Eric R. Love ${ }^{\ddagger}$ (Australia), Danuta PrzeworskaRolewicz ${ }^{\ddagger}$ (Poland), Gary F. Roach ${ }^{\ddagger}$ (UK), Ian N. Sneddon ${ }^{\ddagger}$ (UK)

\section{Honorary Editors:}

Paul L. Butzer (Germany), Michele Caputo (Italy), Ivan Dimovski (Bulgaria), Rudolf Gorenflo (Germany), Mourad E.H. Ismail (USA), Shyam L. Kalla (India), Francesco Mainardi (Italy), Oleg Marichev (USA), Peter Rusev (Bulgaria), Megumi Saigo (Japan), Stefan Samko (Portugal), Jerome Spanier (USA), Hari M. Srivastava (Canada), Bogoljub Stankovic (Serbia)

Associate Editors:

Kai Diethelm (Germany), Yuri Luchko (Germany), Juan J. Nieto (Spain), Ivo Petras (Slovak R.), J.A. Tenreiro Machado (Portugal)

Editorial Board:

Boris Baeumer (N. Zealand), Dumitru Baleanu (Turkey), Emilia Bazhlekova (Bulgaria), Lyubomir Boyadjiev (Kuwait), Yury Brychkov (Russia), Alberto Cabada (Spain), Wen Chen (China), YangQuan Chen (USA), Mark Edelman (USA), Neville Ford (UK), Alan Freed (USA), Rudolf Hilfer (Germany), Niels Jacob (UK), Ravi N. Kalia (USA), Mokhtar Kirane (France), Anatoly Kochubei (Ukraine), Raytcho Lazarov (USA), Changpin Li (China), Richard Magin (USA), Ralf Metzler (Germany), Piotr Mikusinski (USA), Donal O'Regan (Ireland), Igor Podlubny (Slovak R.), Sergei Rogosin (Belarus), Boris Rubin (USA), Jocelyn Sabatier (France), Enrico Scalas (UK), Stepan Tersian (Bulgaria), Juan Trujillo (Spain), Sabir Umarov (USA), Blas Vinagre (Spain), Vu Kim Tuan (USA), Masahiro Yamamoto (Japan), Ahmed Zayed (USA)

\section{Board of Assisting Editors:}

Anatoly A. Alikhanov (Russia), Riccardo Caponetto (Italy), Christophe Farges (France), Roberto Garra (Italy), Roberto Garrappa (Italy), Bangti Jin (UK), Gianni Pagnini (Spain), Andrew W. Wharmby (USA)

Technical Assistant: Stefan Kiryakov (Diogenes Co., Bulgaria)

(C) 2017 Diogenes Co., Sofia

DE GRUYTER 


\section{AIMS AND SCOPE}

\section{Primary topics of FCAA:}

- Fractional Calculus (FC)

- Special Functions and Integral Transforms, related to FC

- Fractional Order Differential and Integral Equations and Systems

- Mathematical Models of Phenomena, described by the above tools

Secondary topics of Applied Mathematical Analysis, iff closely related to FC:

- Algebraic Analysis, Operational and Convolutional Calculi

- Generalized Functions, Harmonic Analysis

- Numerical and Approximation Methods, Computational Procedures and Algorithms, related to the Primary FCAA topics

- Fractional Stochastic Processes

- Fractal and Integral Geometry (if related to FC)

Applications of these techniques to:

- Differential and Integral Equations,

- Problems of Mathematical Physics

- Control Theory, Mechanics, Probability and Statistics, Finances, Engineering, Biomedicine, etc.

\section{Other contributions:}

- If revealing connections between FC and the above-mentioned topics to model problems of the real physical and social world

\section{Suggested MSC 2010 entries:}

- 26A33; 33E12, 34A08, 34K37, 35R11, 60G22 (primary)

- 30C45, 30E15, 31B15, 33C60, 33E30, 34A25, 42A45, 42C10, 44A20, 44A35, 44A40, 45E10, 93B60, 93D09, 05C72, etc.

FCAA journal publishes articles in the following categories:

- Research Papers

- Survey Papers

- Discussion Surveys and Notes, Short Notes, Open Problems

- Archives (renewal publication of old, hardly accessible or in other languages stuff of significant interest for the journal's audience)

- Reviews on Books, Proceedings, etc.

- Editorial Notes - information for New Books, Recent and Coming Meetings, Anniversaries and other events related to FCAA

\section{Submissions:}

All submissions (pdf-file) and queries should be sent electronically

to: Editor-in-Chief, Virginia Kiryakova at virginia@diogenes.bg

Instructions: $\mathrm{AT}_{\mathrm{E}} \mathrm{X}$ typesetting obligatory, use Authors' Kit 